\title{
Implementing Group Work in General and ESP Classrooms in Kuwait's Public Institutions
}

\author{
Abdullah M. Alazemi ${ }^{1}$, Abdullah A. Alenezi ${ }^{1} \&$ Ahmad F. Alnwaiem ${ }^{2}$ \\ ${ }^{1}$ Language Center, The Public Authority for Applied Education and Training, Kuwait \\ ${ }^{2}$ Department of Curriculum and Instruction, College of Basic Education, The Public Authority for Applied \\ Education and Training, Kuwait \\ Correspondence: Abdullah Alazemi, Language Center, The Public Authority for Applied Education and Training, \\ Kuwait.
}

Received: September 29, 2020

doi: 10.5539/elt.v13n11p49

\author{
Accepted: October 21, $2020 \quad$ Online Published: October 22, 2020 \\ URL: https://doi.org/10.5539/elt.v13n11p49
}

\begin{abstract}
Group work (GW) has been at the center of research for many years, and several positive attributes have been linked to its implementation in English language teaching (ELT) classrooms. This study explores Kuwaiti students' views on the benefits and difficulties of GW in their general English and English for specific purposes (ESP) courses. A mixed-method approach, involving both qualitative and quantitative data, was implemented, and 290 individuals responded to the questionnaire of which 22 were interviewed. All participants were students in one of the only two public higher education institutions in Kuwait: Kuwait University (KU) or the Public Authority for Applied Education and Training (PAAET). The findings revealed that the majority of students agreed that GW presented ample benefits for their learning journey, and some of those positive attributes surpassed the education realm into their social and professional realms. However, the findings also showed a few negative issues raised about GW implementation.
\end{abstract}

Keywords: cooperative learning, ESP, group work, motivation

\section{Introduction}

English language teaching and learning have been the center of extensive research in Kuwait. However, even today many students graduating from school and entering the tertiary level continue to face difficulties in English. Their practical and oral abilities do not fall within the intended target level. According to the Ministry of Education (2016) in Kuwait, students graduating from grade 12 should be at the B2 level of the Common European Framework of Reference for Languages (CEFR). However, the majority of students entering universities and colleges are not in this category.

It is therefore important to look for better solutions pertaining to new teaching methods that optimize students' language competence. The aim of this study is to explore group work as a teaching method that could promote better communicative learning outcomes. It also examines any possible disadvantages in implementing group work at different public colleges in Kuwait.

\subsection{The Shift: Communicative Language Teaching}

Communicative language teaching (CLT) developed in the 1970s, influenced by the work of many scholars such as Noam Chomsky and Stephen Krashen. CLT spread in the 1970s and 1980s in response to the shortcomings of traditional teaching methods, such as audio-lingual and grammar-translation methods. Traditional teaching methods focused on grammatical competence, where rules of grammar were presented to students in a continuous manner and then students were given exercises to practice using these rules. In such traditional methods, language learning is conducted in a controlled environment (Long, 1996), and students are expected to produce as many correct sentences as possible while avoiding making mistakes.

As Richards (2006) explained, communicative language teaching necessitated a shift from merely focusing on grammatical competence to acquiring the necessary skills and knowledge to use grammatically correct sentences for different communicative purposes, such as describing situations, giving advice, and making suggestions and requests. Thus, new language teaching methodologies are needed in order to serve such communicative teaching purposes. Classroom methodologies should be tolerant of students' errors and perceive them as part of the 
learning journey; they should also provide students with opportunities to practice what they have learned in real-life situations as well as allow students to build both fluency and accuracy.

\subsection{Student-Centered Classrooms}

In line with the norms of CLT, the shift of focus in the classroom moved from teachers to students. The latter became the center of attention as they were in the middle of the learning journey. Moreover, learners had to be more involved in classroom activities instead of being expected to sit and absorb information presented by the teacher. In CLT classrooms, teachers serve as facilitators and monitors as students begin taking control of their own learning by listening to their peers and interacting with them in group work and pair activities.

In a communicative classroom, the teacher sets the activity and provides the necessary tools needed; it is the learner's role to act out the activity from beginning to end, with the help of the teacher when needed. Hamza (1994) explained that the learner should be able to understand what kinds of experiences and inputs ought to be encountered, how to make sense of them, and how to go beyond the information given to draw generalizations from the content. Such a role does not minimize the importance of the teachers in the communicative classroom, as they need to guide students and encourage them to make decisions as well as discuss and negotiate among themselves. Teachers should also make use of the input they gain from students to identify their strengths and weaknesses and shape the coming activities to cater to their needs. Such a step will help teachers provide a better learning environment and maximize students' learning experience.

\subsection{Group Work}

Group work (GW) is a student-centered way of teaching that helps students learn through interaction with each other in authentic contexts (Rance-Roney, 2010). Therefore, group work encourages students to work in teams, accomplish tasks, and construct knowledge through collaborative learning. The major theoretical hypotheses to second language learning (input, output, interactional hypothesis, and sociocultural theory) have weighed in on the importance of group work in promoting students' language abilities. Moreover, GW offers students a better chance at experiencing meaningful learning, which in return leads to longer retention than rote learning (Brown, 2001).

In other words, GW moves students from a textbook-learning atmosphere to one in which they experience face-to-face practices, negotiate meaning, adopt roles, and exchange real-life conversations. In this way, learning becomes more relevant, contextualized, and appealing to students and moves them away from the memorization and drills found in indoctrination processes. As Salas (2005) put it,

group work supports and reinforces the application of the multiple intelligences theory in which learners make use of their individual abilities to accomplish a task. In this way, learners can participate by doing what they like or are very good at, for example, drawing, writing, reporting, among others. (p. 4)

In this case, students are able to express their own ability in a secure environment; thus, learners' autonomy and responsibility are encouraged.

Several studies have been conducted in this area, reflecting the effectiveness of group work as a method of teaching. Alfares (2017) explored Saudi students' benefits and difficulties when engaging in group work in English as foreign language (EFL) classrooms. The results indicated a general consensus regarding many benefits, all relating to the development of their knowledge of the language, motivation to learn, and academic learning. Chiriac (2014) conducted research to elucidate students' positive and negative views on group work and how they affected their academic achievement. The findings indicated that the majority of students believed group work facilitated their learning; they also benefited in other areas, such as by building their collaborative abilities.

\section{Purpose of the Study}

The Kuwaiti government recognizes the importance of English and has therefore consumed a lot of resources to promote better English language teaching (ELT) and learning. The ELT learning objectives are well stated and focused. However, the de facto practices are far from this idealistically written reality. Although the Ministry of Education has promoted the implementation of the communicative language approach when teaching English and set the general aims of teaching as providing students with new modern ways of language acquisition while leaving behind the "old-fashioned" skill-drilling methods that are textbook oriented (Ministry of Education, 2016), the de facto practices still rely on drilling techniques as well as teacher-centered classrooms. Classroom distribution is based on rows, keeping students distant from each other-a layout that does not appropriately utilize students' potential. These education errors that contradict the core of communicative language teaching 
are also extended to the tertiary level. Students advance to higher education with such a mentality, as they are used to receiving rather than producing language and negotiating proper language meaning. Thus, the Ministry of Higher Education needs to promote better teaching methods rather than continuously focusing on changing the curriculums.

Alazemi (2017) mentioned little research has been conducted to thoroughly evaluate the current trends in English language teaching in Kuwait. He also demonstrated how the current teaching practices are more in line with the grammar-translation method and audio-lingual method tenets than the communicative approach tenets. The former methods focus on content rather than language use. Researchers in Kuwait have raised several critical issues for decades, such as teacher-centered classrooms and distribution of classrooms, but these issues have yet to be resolved. The continuity of such ideologies, which support student separation and teacher-centered classrooms, hinder the development of students' language skills.

According to Kuwait University (2016), students have a general overall weakness in their command of English when they reach the university level. Its report also acknowledged that $62 \%$ of the university's students resort to private tuition, which has become more of a phenomenon. Alshatti and Sabti (2012) corroborated such findings, as they found that secondary students attend private tutoring in order to improve their language abilities. Existing research in Kuwait (Al-Rabah et al., 2016) has shown the positive attributes of GW in exposing students to the second language and providing them with adequate opportunities for negotiating meaning. When teachers do not employ communicative teaching methods, students can receive new language knowledge, but not be able to produce it.

Such findings, as well as those found in similar neighboring countries, show that a critical and major intervention is needed. Schools and universities need to address these problems by implementing new teaching methods rather than merely changing curriculums. The current study argues that GW is one of the many solutions that could enable students to promote their language abilities. The current study implements an exploratory method that aims to explore learners' perceptions toward the benefits of GW in promoting better language abilities. It also aims to investigate their attitudes toward group work and determine whether any barriers hinder such progression.

Furthermore, the study focuses on students from Kuwait University (KU) and the Public Authority for Applied Education and Training (PAAET) - the only two public higher education institutions in Kuwait. These institutions teach $85 \%$ of school graduates (Alazemi, 2017), making it a logical choice to evaluate their teaching methods and investigate students' perceptions of GW in both their general and English for specific purposes (ESP) modules. Both institutions claim to have student-centered classrooms and aim to equip students with the necessary language abilities to prepare them for the job market.

Two research questions have been developed to achieve the aim of the study:

1) What are the benefits of group work as identified by Kuwaiti EFL students?

2) What are the disadvantages of group work as identified by Kuwaiti EFL students?

\section{Methodology}

This study implements a sequential mixed method design, thereby adopting both qualitative and quantitative methods of data collection, although more weight is given to the qualitative data as such information is more suitable for answering the research questions. In the first stage, a closed-ended item questionnaire with a 5-point Likert scale was used. The questionnaire consisted of 22 items that were divided into 3 sections; (1) demographic information, (2) benefits of GW, and (3) issues related to GW. In the second stage, semi-structured interviews were conducted, and participants were selected based on the criteria that they had already completed the first stage and were willing to participate in the interviews. The interviews were conducted by the first author in Arabic, and they were transcribed for predetermined specific themes that aimed to look at the benefits and disadvantages of group work. The importance of such a methodology allows one method to support the other and devise a better outcome (Bryman, 2012; Perry, 2011). It also helps gather as much information in the first stage to better focus the questions in the second stage (Dörnyei, 2007). This will allow for presenting thorough insights into the investigated phenomenon and elicit the participants' views in a deeper scope.

Therefore, after administering the questionnaire and analyzing the answers, the questions for the interviews were developed and analyzed. Both methods underwent a pilot study to address any discrepancies and misunderstandings and ensure the validity of both methods. The pilot study included 22 students, both males and females, from KU and PAAET. A few modifications were made to the sentence order of some questionnaire items after the pilot study to minimize any possible confusion. 


\section{Data Collection}

Participants were purposively chosen from KU and PAAET because these public institutions ought to be aligned with the objectives of public secondary schools. Students from both institutions were randomly selected from different genders, disciplines, ages, and years of study. Participants had to meet certain general criteria to be eligible:

1) Be a current student in a public higher education institute

2) Have graduated from a public school

3) Have enrolled in at least one ELT course

4) Have experienced group work in an ELT classroom at their current institution

The researcher contacted the two institutions for consent to conduct the research; approval was obtained from both relevant English departments. During the first stage, the questionnaire was distributed to the students and administered by the researcher. Students willing to participate in the interviews were asked to provide their contact information. During the preparation of the second stage, students were asked to sign a consent form, and it was made clear to them that they had the choice to not respond to any question for any reason. In total, 290 students completed the questionnaire of which 22 (14 males and 8 females) participated in the interview stage. The participants ranged from 18 to 23 years old, from different university years and several science disciplines. For the questionnaire, 150 students were from KU and 140 from PAAET; and for the interviews. 12 students from KU and 10 from PAAET.

\section{Results}

The results indicated a general positive tendency toward GW, although several negative points also emerged. Two major themes were identified based on the findings: the positive tendency, which encompasses both academic and personal gains, and the negative tendency, which also encompasses both academic and personal gains.

\subsection{Benefits}

\subsubsection{Positive Academic Gains}

The majority of participants (87\%) explained how GW proposes many positive academic attributes. They illustrated that it helps them learn the content better, as Hanoof echoed a shared point with her colleagues during her interview:

I have many opportunities to understand the intended content when it is an active classroom. For example, in a formal lecture I only have the opportunity to learn from the teacher, and if I miss anything then that is it. But in GW I can discuss and ask without interrupting the flow of the lessons.

\begin{tabular}{llll}
\hline Item & Agree & Neutral & Disagree \\
\hline Working in groups helps me learn the course content better & $82 \%$ & $6 \%$ & $12 \%$
\end{tabular}

Several students shared that GW provides more teaching opportunities, as they are able to listen to both the teacher and their peers. Furthermore, $82 \%$ of the questionnaire respondents agreed that $\mathrm{GW}$ improved their academic competence, which was a point mentioned by the majority of participants on both the questionnaire and/or in the interview. According to Hanoof and some of her colleagues, this "multiple source" input allows students to ask their peers when they miss something rather than allowing the information to slip away, which is especially useful if they feel shy about interrupting the lesson.

In addition, according to both questionnaire and interview results, $86 \%$ of participants believed that GW opens pathways to new knowledge and experiences. Ali explained that discussing and engaging in conversations with colleagues allows students to share knowledge:

When I am asked to do a task with my colleagues, we all have an extra opportunity to explore new information. For example, one of us could present new information and/or we could exchange new ideas about a certain task we are doing. Different students have different ideas, so the discussion will be rich and full of new knowledge.

19 other interviewees as well as $90 \%$ of the questionnaire respondents agreed with this statement. Students explained that discussing ideas with several students increases the possibility of attaining new knowledge. The different experiences and backgrounds that students bring to GW make it a rich experience that provides them with ample benefits. In GW students are also able to help their colleagues by explaining the content, as Talal illustrated: "We are able to help each other and explain to each other because we understand what we go 
through, and our language level most of the times is close so we can deliver the content in a simpler way." Talal explained that students are able to help each other better in GW because of a mutual understanding - namely, they have similar experiences and go through the same learning process. This could help students as they understand each other better and go through the same learning problems. Furthermore, teachers usually teach the whole class without focusing on individual differences, so their colleagues could provide an additional explanation that suits their level.

Other students explained how GW was an excellent exercise to practice their speaking skills. Mariam clarified:

During group work we can practice our speaking skills and improve them because we continuously work in our groups and talk to each other. Furthermore, we do every exercise with each other, so we tend to have more time to speak. More importantly, during $G W$ we are talking to our friends and colleagues, so we are more relaxed.

Mariam indicated how GW provides an exciting and familiar environment for students. This environment helps them develop their command of English, as they feel more comfortable when speaking and listening within a supportive atmosphere.

\subsubsection{Overcoming Obstacles}

Both interviewees and questionnaire respondents noted how GW allowed them to overcome certain limitations that hindered their English learning progression. These limitations have set students back and did not allow them to develop properly. For example, students explained that GW helps them overcome shyness and thus practice certain skills. Aziz stated that:

Many students have a shyness problem; they are scared of making a mistake and coming across as "fools." The problem is that, when you are shy, you do not have the opportunity to practice the language. Students do not trust themselves with the language because they do not use it a lot. As the saying goes "practice makes perfect." GW allows us to speak in a safe environment; we (students) feel more comfortable talking to each other.

Aziz described how GW provides students with enough room to express themselves in English because they overcome shyness, which is a daunting obstacle that many students face. Students are shy because they do not want to seem incapable in front of their colleagues, so they refrain from participating, which consequently leads to hindering their learning/teaching process. GW comes as a safe gate for them to practice their speaking with no tension or pressure, leading to a better learning experience. These findings were also supported by the questionnaire results, as $80 \%$ of the respondents agreed that GW helps them overcome shyness.

One of the major obstacles that students face when learning English is the loss of motivation, and the participants believed that GW helped them be more motivated and willing to engage in tasks and exercises. They felt that, when learning alone, they do not have the necessary motivation to practice their language skills. Furthermore, they preferred to be passive learners during teacher-centered classrooms. As Huda explained:

Usually in teacher-centered classrooms I do not have the energy and/or the drive to participate, engage, and learn. I would prefer to sit the whole class doing nothing and waiting for the lessons to end rather than be motivated and engaged with the needed tasks. However, with GW it is more fun and we are happy to do the tasks. I feel like a different student when I am in a class that implements GW-you really feel the need to engage, talk, and discuss with our friends.

\begin{tabular}{lccc}
\hline Questionnaire Item & Agree & Neutral & Disagree \\
\hline Working in groups makes lectures more exciting and fun & $88 \%$ & $2 \%$ & $10 \%$ \\
\hline
\end{tabular}

Huda agreed with $88 \%$ of the questionnaire respondents and other interviewees that GW made English classrooms exciting and engaging, which led to increased motivation. They indicated how GW made them active rather than passive learners, as it allowed them to participate more and engage in a more fruitful environment. As Khaled stated:

In our classrooms we usually have 35 to 45 students and the duration is only 1 hour, so teachers do not have time to make sure that everyone is participating and practicing. Therefore, GW helps overcome the issue of crowded classrooms and enables students to have an equal opportunity to talk, discuss, and participate. 
Students such as Khaled expressed how GW overcomes issues pertaining to overcrowded classrooms. Other students stated that classrooms with more than 60 students made it impossible to participate and engage. They found GW to be a way to practice their language skills.

5.1.3 Personal Gains

\begin{tabular}{llll}
\hline Questionnaire Item & Agree & Neutral & Disagree \\
\hline Working in groups allows me to acquire other personal skills, such as & $87 \%$ & $1 \%$ & $12 \%$ \\
debating, communicating with others and becoming more & & & \\
self-confident & & &
\end{tabular}

Interestingly, 78\% questionnaire respondents associated GW not only with academic gains, but also with personal ones. These ranged from communication skills to debating skills. Thus, the benefits of GW go beyond the academic realm to include the social world. Several students illustrated how their communication skills improved because of GW. They explained that being able to talk, discuss, and debate honed their communication skills, and they were able to better negotiate meaning with others. As Salma explained:

It is not just about practicing the language. I rarely get the opportunity to discuss and talk with other colleagues. These discussions and talks help me become a better communicator and understand when to listen, stop, or talk. [GW] gave me multiple opportunities to discuss and debate with other colleagues. I believe its benefits are beneficial in several ways.

In addition, $89 \%$ of questionnaire respondents agreed with this statement. They believed that GW helped them attain better communication skills as well as improve other non-academic skills that would help them later in life. Furthermore, other students showed how GW allowed them to gain self-confidence. It gave them the necessary attributes to speak out and talk with others, as Hamed demonstrated:

Being able to talk and express my opinion is a huge advantage for me, and it boosted my confidence. As you know, most of the time we are not allowed to express ourselves and talk with others, so being able to do that in class and in a safe environment is a great advantage. After engaging in several $G W$ exercises, I saw myself more relaxed when talking and sharing my opinion.

Such beliefs of the benefits of GW were also expressed in the questionnaire responses, as $85 \%$ of the respondents believed it made them gain more confidence in speaking in a general sense. Thus, all those who participated in this study agreed on this point. Interestingly, students also believe that GW helps them with social relations. They seemed to see GW as a gateway to social interactions and gaining new friends. As Jassim stated:

I truly believe that GW helps us to break social boundaries. Usually we (students) do not have the chance to interact with each other, we just enter the class, listen, and then leave when the lecture is over. So, there are no other opportunities for us to meet and talk with our colleagues. With group work things are different; we have the chance to sit with each other, and the academic discussions break down the distance between us.

Students such as Jassim explained that they usually attend a lecture and leave, which does not allow them to talk or sit down with their colleagues. They also mentioned the idea that these in-class discussions could lead to friendships, as sitting with someone several times over a few months could build a solid relationship. Several students raised the issue of attentiveness and focus, as the group work or group discussion is directed along a different path. This issue, according to students, comes in different forms, as Faisal explained:

It is sometimes difficult to function as a good group, it could sometimes be frustrating. Sometimes several members of a group will take it as a chance to talk about topics unrelated to the lecture and they start to chitchat about football, movies, or what they did last night. Even when they discuss the intended content or exercise, sometimes they get sidetracked by other academic but non-related topics.

\subsection{Difficulties}

GW was not free of negative affiliations; study participants identified several potential issues, ranging from those related to an academic matter to group functionality. Some participants explained how some students tended to shift the focus of the exercise or class work they were doing, creating more of a distraction. As Ahmed explained:

Sometimes during GW some students begin talking about non-related topics. For example, they begin to talk about what they learned in other courses or their previous experience, which is something that does 
not concern us. Unfortunately, this happens a lot, and our time is wasted on topics that are not related to what we are doing.

Students such as Ahmed believe that they are sometimes sidetracked during group discussions, as others tend to shift the discussion to other topics. This leads them to prefer studying alone as they see GW as a waste of time. Furthermore, students expressed their concern that usually one student leads most of the discussions and takes control of how things go in the group. Usually this student has the highest level of English. As Nasser expressed:

During group work or discussion, it is mainly the student with the highest level of English who controls how the work goes. Other students tend to listen and follow because they believe that he is the most capable in finishing the tasks. Therefore, they tend to sit and do nothing whilst the other student does most of the work. They even sometimes just nod their heads.

The majority of questionnaire respondents $(69 \%)$ agreed that those with a high command of English usually take over the group. The rest disagreed, with some interviewees stating that this rarely happens. This result could be due to the fact that they have a good command of English and usually get involved or that the teachers distribute the students effectively and assign different tasks to them.

\begin{tabular}{llll}
\hline Questionnaire Item & Agree & Neutral & Disagree \\
\hline All group members should have the same score & $71 \%$ & $7 \%$ & $22 \%$
\end{tabular}

Another issue raised about GW related to the academic matter of assigning grades. Some students discussed the issue of giving the same score to all group members regardless of how much effort they put in. The results from the questionnaire showed that $71 \%$ agreed that all group members should have the same score. During the interviews, students explained this matter in detail. Habib said:

It is fair for all members to get the same score; even if some do more than others, it all comes down to what everyone puts in. Yes, some will say that others do not do a lot or some members are reliant on other members to do the task, but how can you know who did what? Who has the right to say who deserves what? Because the teacher will not be able to monitor everyone.

Students explained that it is the contribution itself that matters rather than the quantity of it. They argued that everyone contributes according to their capabilities, and that is what counts.

\section{Discussion}

Learning a new language can be a daunting process as it requires a lot of effort, time, and concentration. Thus, it needs to be engaging and exciting to motivate students to reach the best possible outcome. Educational and language institutions continuously aim to find the necessary means to provide a beneficial experience to their students. One of those solutions is implementing GW in English learning/teaching classrooms. Although some negative issues were raised, the results of this study reflected many positive attributes of GW.

Participants explained that, in groups, they are able to discuss, ask for feedback, and request more clarification from other colleagues. This helps them improve their acquisition of the target language. Such findings support previous research on the role of the interaction hypothesis in second language acquisition (Ellis, 1997; Long, 2007), whereby students implement certain strategies such as paraphrasing, speaking more deliberately, or slowing down their speech (Brown, 2014). It seems the interaction caused by GW provides students with multiple sources of knowledge of the intended content. Students also expressed that this interaction made the learning process fun and exciting; it encouraged them to participate more and become engaged in class activities. Such findings are in line with other research, as Greenop (2007) reported how students enjoyed discussing, talking, and hearing other students' ideas and opinions. Furthermore, classroom discussions should not only be with teachers, as students should also discuss and talk amongst themselves. Thus, GW also shifts the learning environment from a teacher-centered classroom to a student-center classroom.

We need to understand that a positive learning environment ensures a better learning outcome. Research has shown how learning a new language causes comprehensibility issues (Habbash \& Troudi, 2015) and could lead to several pedagogical and linguistic barriers (Skutnabb-Kangas, 2009). Therefore, educational institutions need to find the necessary tools to help their students engage in a positive learning experience. Students will eventually do better as long as they feel satisfied about themselves (Canfield, 1990). The findings of this study reflected how students enjoy themselves in GW and it motivates them to become active learners. It also allows them to overcome their shyness, which is an overwhelming obstacle that hinders students from practicing the language in class and maximizing the benefits. 
Indeed, participants indicated how shyness is a major problem when trying to learn a new language. They are afraid of making mistakes, as they believe it makes them come across as inferior to their colleagues. Alazemi (2017) noted similar findings, as students were hesitant to raise their hands and answer because they were shy or afraid of making mistakes. GW put them in a safe environment where they felt safe to practice the tasks and engage in fruitful learning (Burke, 2011), an environment where they were able practice what they learn without feeling overwhelmed with stress and shyness.

From a non-academic perspective, the results also show that GW empowers students with a set of certain social skills. These skills will help them develop in non-academia fields as they become better communicators and listeners (Kasim, 2015). They could also be equipped with better managerial skills for working with groups, delegating roles, assigning tasks, and generally working in a group environment. Thus, it could be argued that GW better prepares them for their social lives, as it develops their interpersonal skills (Burke, 2011). Such findings have been echoed in other research in the area (Taqi \& Al-Nouh, 2014), as students expressed how they felt that they were gaining more than learning the intended content. In addition, at the international level, Frykedal and Chiriac (2012) found that GW helps students socialize and interact at the social and personal levels - a finding also echoed in the current study. Students in this research expressed that, during GW, they had more time to build friendships and more opportunities to engage in conversations with their colleagues whom they rarely talk to in non-GW classrooms.

Research has also found that GW enhances other professional development skills, such as enabling students to perform critical skills for processing information (Bennett \& Gadlin, 2012). Furthermore, it engages them in assessment skills, as they discuss and assess several options to reach a final group conclusion, and management skills, because they learn how to properly execute a role given to them in their groups (Jackson et al., 2014). The findings of this study, as well as those of other research, suggest that the benefits of GW go beyond the small class or learning environment, as the positive aspects attached to it could help students later in life. Thus, it becomes an opportunity for students to learn content as well as practice skills that could have a progressive effect later in life.

However, GW also presents certain disadvantages. Students stated that, in some cases, one person controls most of the group while the rest tend to listen and agree. Such an issue is not new to GW, as many instructors find it easy to randomly select group members instead of assigning certain roles, which could lead to an imbalanced group that causes such issues (Burke, 2011). Similar findings were found in other research in the Arabian Gulf area (Alfares, 2017) and in other parts of the world (Frykedal \& Chiriac, 2012; Seric \& Pranicevic, 2018). The results also show that some students tend to socialize in groups, which is usually caused when students self-select their own groups. However, research shows that groups assigned by teachers usually perform better than those selected by the students themselves (Felder \& Brent, 2001). Students have different learning objectives according to their competency level in English; some students take a long time to understand a task whereas others want to move on and still others just want to utilize the time to talk about personal matters. These issues need to be considered by teachers when distributing groups.

Furthermore, it appears that students think about grade distribution in GW, as their viewpoints differ in grading the group as a whole or individually. Such views have been expressed in earlier research, where it seems to be a common topic amongst students around the world. As Burke (2011) explained, group evaluation is a difficult task. If students are evaluated as a group, then it could spread a sense of unfairness; if evaluated individually, it could destabilize group solidarity (Davis, 1993). The implication for teachers here is to clearly explain to students the evaluation process by setting out a clear grading rubric. According to Stevens and Levi (2005), a rubric will help reduce grading time for teachers and help students to focus their efforts, thereby improving their achievement.

An important implication for teachers is to take care of how groups are formed and roles are distributed as well as how they function. In order to ensure the utmost benefit of groups, teachers need to monitor how groups work and ensure that every student is involved by assigning specific roles. Teachers also need to walk around the classroom and check that all students are properly working within their groups. As Bolton (1999) explained, teachers still need to do student coaching, offering observations, suggestions, and insights to groups as needed.

\section{Conclusion}

GW offers ample benefits, both academically and socially. The bulk of evidence in this study showed that an overwhelming majority of students recognized the positive environment GW created, which helped them better understand the course content, provided them with multiple sources of knowledge, and more importantly 
motivated them. Although several negative issues were also raised, the majority of them could be addressed through more teacher intervention, monitoring, and effective observations of how students function.

This study, as well as previous research, has shown the importance of GW in EFL and English as a second language classrooms. With proper administration and preparation, GW could benefit students on many levels. It is not enough for teachers to merely state the task and leave students to work out the rest, such as distributing roles, developing the groups, and determining how they function internally. It is the teachers' role to ensure that the groups work at a high level of functionality (Bolton, 1999).

\section{References}

Alazemi, A. (2017). Teaching of academic subjects in English and the challenges Kuwaiti students face [Unpublished master's thesis]. The University of Exeter.

Alfares, N. (2017). Benefits and Difficulties of learning in group work in EFL classes in Saudi Arabia. English Language Teaching, 10(7), 247-256. http://doi.org/10.5539/elt.v10n7p247

Al-Rabah, S., Wu, S., Alotaibi, A., \& Aldaihani, H. (2016). English teachers' use of learners' L1 (Arabic) in college classrooms in Kuwait. English Language Teaching, 9(1), 1-11. http://doi.org/10.5539/elt.v9n1p1

Alshatti, S., \& Sabti, A. (2012). The impact of spending on private tutoring on the Kuwaiti family budget. Almanshawi, 12(5), 1-7.

Bennett, L. M., \& Gadlin, H. (2012). Collaboration and team science: From theory to practice. Journal of Investigative Medicine, 60(5), 768-775. https://doi.org/10.2310/JIM.0b013e318250871d

Bolton, M. K. (1999). The role of coaching in student teams: A 'just-in-time' approach to learning. Journal of Management Education, 23(3), 233-250. https://doi.org/10.1177\%2F105256299902300302

Brown, H. D. (2001). Teaching by principles: An interactive approach to language pedagogy. Addison Wesley Longman.

Brown, H. D. (2014). Principles of language learning and teaching: A course in second language acquisition (6th ed.). Pearson Education ESL.

Bryman, A. (2012). Social research methods (4th ed.). Oxford University Press.

Burke, A. (2011). Group work: How to use groups effectively. The Journal of Effective Teaching, 11(2), 87-95.

Canfield, J. (1990). Improving students' self-esteem. Educational Leadership, 48(1), 48-50.

Chiriac, E. H. (2014). Group work as an incentive for learning: Students' experiences of group work. Frontiers in Psychology, 5, 1-10. https://doi.org/10.3389/fpsyg.2014.00558

Davis, B. G. (1993). Tools for teaching. Jossey-Bass Inc.

Dörnyei, Z. (2007). Research methods in applied linguistics. Oxford University.

Ellis. R. (1997). Second language acquisition. Oxford University Press.

Felder, R. M., \& Brent, R. (2001). Effective strategies for cooperative learning. Journal of Cooperation \& Collaboration in College Teaching, 10(2), 69-75. https://doi.org/10.1021/bk-20070970.ch004

Frykedal, K. F., \& Chiriac, E. H. (2012). Group work management in the classroom. Scandinavian Journal of Educational Research, 5(56), 1-13. http://doi.org/10.1080/00313831.2012.7225098

Greenop, K. (2007). Students' perceptions of efficacy and preference for two lecture formats. South African Journal of Psychology, 37(2), 361-367. http://doi.org/10.1177/008124630703700212

Habbash, M., \& Troudi, S. (2015). The discourse of global English and its representation in the Saudi context: A postmodernist critical perspective. In R. Raddawi (Ed.), Intercultural communication with Arabs: Studies in education, professional and societal contexts. Springer. https://doi.org/10.1007/978-981-287-254-8_5

Hamza, A. (1994). The communicative approach: Practising teachers' perceptions versus the theory [Unpublished MA dissertation]. University of Liverpool.

Jackson, D., Sibson, R., \& Riebe, L. (2014). Undergraduate perceptions of the development of team working skills. Education+ Training, 56(1), 7-20. https://doi.org/10.1108/ET-01-2013-0002

Kasim, U. (2015). Implementation of group work in the classroom. Lingua, 12(1), 97-106. https://doi.org/10.30957/lingua.v12i1.74

Kuwait University. (2016). Kuwait University statistics. The Office of The Vice President for Planning, 1-7. 
Long, M. (1996). The role of the linguistic environment in second language acquisition. In W. Ritchie \& T. Bhatia (Eds.), Handbook of language acquisition. Second language acquisition (pp. 413-468). Academic Press. https://doi.org/10.1016/B978-012589042-7/50015-3

Long, M. H. (2007). Problems in SLA. Routledge.

Ministry of Education. (2016). Aims of the Ministry of Education. Retrieved from http://www.moe.edu.kw/about/Pages/philosophy.aspx

Perry, F. (2011). Research in applied linguistics: Becoming a discerning consumer (2nd ed.). Routledge. https://doi.org/10.4324/9780203839027

Rance-Roney, J. A. (2010). Reconceptualizing interactional groups: Grouping schemes for maximizing language learning. English Teaching Forum, 10(1), 20-26.

Richards, J. C. (2006). Communicative language teaching today. University of Cambridge Press.

Salas, M. R. (2005). Grouping techniques in an EFL classroom. Revista Electrónica "Actualidades Investigativas en Educación," 5, 1-14. https://doi.org/10.15517/aie.v5i3.9167

Seric, M., \& Pranicevic, D. G. (2018). Managing group work in the classroom: An international study on perceived benefits and risks based on students' cultural background and gender. Journal of Contemporary Management Issues, 23(1), 139-156. https://doi.org/10.30924/mjcmi/2018.23.1.139

Skutnabb-Kangas, T. (2009). What can TESOL do in order not to participate in crimes against humanity? TESOL Quarterly, 43(2), 340-344. https://doi.org/10.1002/j.1545-7249.2009.tb00176.x

Stevens, D. D., \& Levi, A. J. (2005). Introductions to rubrics: An assessment tool to save grading time, convey effective feedback and promote student learning. Stylus Publishing.

Taqi, H. A., \& Al-Nouh, N. A. (2014). Effect of group work on EFL students' attitudes and learning in higher education. Journal of Education and Learning, 3(2), 52-65. http://doi.org/10.5539/jel.v3n2p52

\section{Copyrights}

Copyright for this article is retained by the author(s), with first publication rights granted to the journal.

This is an open-access article distributed under the terms and conditions of the Creative Commons Attribution license (http://creativecommons.org/licenses/by/4.0/). 